\title{
Herondas por Herondas: autoficción en el mimo helenístico
}

\section{Claudia N. Fernández}

\section{Résumé}

Claudia N. Fernández, Herondas por Herondas : autoficción en el mimo helenístico.

Ce travail propose une étude de l'image de l'écrivain qui s'inscrit au sein de la production d'Hérondas. À ce propos, on suggère une révision des passages métafictionnels - surtout ceux qui se présentent à l'intérieur des mimes VIII, IV et VI - capables de dévoiler comment l'auteur réussit non seulement à construire sa voix poétique, mais aussi à contrôler le rapport avec son public et à affirmer ses attentes concernant la façon dont il doit être lu. Ces passages permettent ainsi de revenir sur les réflexions autour du type de récepteur historique de ces courts drames hellénistiques.

\begin{abstract}
In order to explore the writer's image inscribed in Herondas's work, this paper examines metafictional passages - mostly those of mimes VIII, IV and VI - that reveal how Herondas not only constructs his poetic voice but also takes control of the relationship with his audience, and furthermore, reveals his expectations concerning how he should be read. Such passages induce a rethinking of who were the historic receptors of these little Hellenistic dramas.
\end{abstract}

\section{Citer ce document / Cite this document :}

Fernández Claudia N. Herondas por Herondas: autoficción en el mimo helenístico. In: L'antiquité classique, Tome 75, 2006. pp. 23-39;

doi : https://doi.org/10.3406/antiq.2006.2590

https://www.persee.fr/doc/antiq_0770-2817_2006_num_75_1_2590

Fichier pdf généré le 07/04/2018 


\section{Herondas por Herondas: autoficción en el mimo helenístico}

La publicación de los papiros que contenían los mimos de Herondas, en 1891, dio a conocer un "género insospechado dentro de la poesía helenística", de cuya existencia, hasta ese momento, solo daban testimonio unas pocas citas de lexicógrafos antiguos. En un comienzo el valor de este nuevo material se limitó al carácter singular de su supervivencia. Se trataba de siete mimos completos y el fragmento de un octavo, este último editado unos años más tarde. Hoy en día, en cambio, se reconoce en estos pequeños dramas poéticos - sigue siendo una cuestión debatida por la crítica su índole teatral ${ }^{2}$ - mucho del virtuosismo literario típico de la obra de los consagrados contemporáneos Teócrito y Calímaco.

Es dable suponer que en época clásica el mimo fuera una forma dramática alternativa de divertimento popular y ocupara, entonces, un lugar relegado en el circuito de las representaciones teatrales oficiales, instancia que suele servir para explicar los escasos testimonios que han sobrevivido de su época primera. Esta limitación evidente, sin embargo, no ha sido impedimento para que se postularan, al menos desde el siglo $\mathrm{V}$, dos variables tipológicas dentro del género, la literaria y la popular, si no opuestas, al menos discernibles en atención al significado de los rótulos que las designan. El mimo literario se remonta habitualmente a la figura del siracusano Sofrón, reconocido especialmente por las citas aristotélicas que lo vinculan con Platón y la forma dialogada de su obra fílosófica. ${ }^{3}$ Tal como está planteada, esta dicotomía del género falsea la cuestión al enfocarla unilateralmente desde la perspectiva del

1 A. MELERo, "Consideraciones en torno a los mimiambos de Herodas", CFC 7 (1974), p. 303.

2 La cuestión es determinar si fueron escritos para ser leídos (Buchpoesie) o para ser representados, ya sea por uno o varios actores. Sin duda G. MASTROMARCO (Il pubblico di Eronda, Padova, 1979) ha sido el principal defensor del carácter esencialmente dramático del mimo y de su efectiva puesta en escena, en teatros o en ámbitos cerrados, como el del simposio o el de la corte. La solidez de sus argumentaciones nos induce a compartir sus hipótesis. A la hora de tomar una decisión conclusiva al respecto reparamos que no es menos cierta, sin embargo, la siguiente observación de R. HUNTER, "The Presentation of Herodas' Mimiamboi", Antichton 27 (1993), p. 31-32: "A feature which looks as if it derives from the script of an acted, or at least visualized, performance may always be merely a literary imitation of such a phenomenon within a text intended only for reading (or, at most, recitation)."

3 Cf. ARISTóteles, Poética, 1447b. Sofrón inaugura normalmente una lista de mimógrafos compuesta por nombres como los de Jenarco, Focio, Hermeias y Nicias. Sin embargo solo del propio Sofrón nos han llegado algunos fragmentos, en prosa rítmica y en su dialecto dórico nativo. Sobre la cronología del género, ver E. Wüst, "Mimos", RE XV (1932), col. 1727 ss. 
autor y de la creación literaria. ${ }^{4}$ A nuestro entender, si se enfocase el fenómeno desde la perspectiva de la audiencia, para decirlo de otro modo, si se pudiese determinar el alcance y estrato social de su público, el mimo llamado "literario" podría catalogarse de popular, ${ }^{5}$ y hasta de "performativo", no para ser leído sino representado.

Estas mismas categorías, no obstante, han parecido en principio menos arbitrarias para calificar a la mimografía de la época helenística, porque en estos tiempos post-clásicos la distinción entre lo literario y lo popular daría cuenta de la dicotomía entre la cultura hegemónica griega, producida por la clase gobernante, y la cultura subalterna, propia del pueblo colonizado. Esta confrontación instruiría sobre la situación de la Alejandría ptolomeica, al abrigo de cuya corte habría escrito Herondas sus mimos - o mimiambos, como Estobeo dio en llamar a tales composiciones dramáticas escritas en coliambos.

Pero ¿quién fue Herondas? ${ }^{7}$ Desde la publicación de los papiros fue una de las preocupaciones de la crítica dar una respuesta a esta pregunta. Datos internos a su obra dieron en suponer que vivió alrededor del $270,{ }^{8}$ pero no puede determinarse con certeza que haya residido en Cos, como algunos sostienen. ${ }^{9}$ El nombre del autor, por su parte, sugiere un origen dorio. Sus composiciones responden a la tradicional defini-

4 Efectivamente se llama literario al mimo fijado en un texto, con una dicción más o menos artística, y por ello diferente de las manifestaciones anónimas e improvisadas del mimo popular (MELERO, l.c. [n. 1]).

5 Ha resultado de compleja delimitación el concepto de "lo popular". En algunos casos, se denomina "popular" todo aquello que consume la gente (lo que lee, escucha, compra, disfruta, etc.), pero, otras veces, designa lo que emana de la gente. En ambos casos la cultura popular se caracteriza por su falta de autonomía y su llamativa diversidad. Efectivamente, la cultura popular se encuentra casi siempre en una tensión constante (de influencia y contraposición) con respecto a la cultura dominante. Ver al respecto J. Frow, Cultural Studies and Cultural Value, Oxford, 1995.

6 Si el mimo llamado "literario" se representaba en un edificio teatral, y no en el ámbito cerrado y aristocrático del simposio, bien podría caberle el mote de "popular", en atención al alcance masivo de su repercusión y en franca oposición a la literatura de la "elite". La denominación utilizada por HUNTER, l.c. (n. 2), de "mimo literario" y "subliterario", hace hincapié en el carácter escriturario de la creación, en un caso, y en su indole improvisada, en el otro, y opondría menos reparos. Sobre los espacios posibles de la representación, ver I.C. CunNingham, Herodas: Mimiambi, Oxford, 1971, p. 4-5. Las citas de los mimos son tomadas de esta edición.

7 Seguimos la denominación defendida por J.A. NAIRN, L. LALOY, Hérondas: Mimes, Paris, $1960^{2}$, frente a la mayoría de la crítica que adopta la forma Herodas.

8 No es ésta una fecha incuestionable. La datación se basa primordialmente en la mención a Ptolomeo Filadelfo y su hermana consorte Arsínoe en el mimo primero (v. 30). El cuarto poema puede ser fechado entre el 280 y el 265, por la referencia a los hijos de Praxiteles y a Apeles, y el segundo probablemente haya sido escrito antes del 266 , por la referencia a la ciudad fenicia de Ake, que entre el 286 y 266 fue rebautizada Ptolemais.

9 El mimo segundo, y presumiblemente el cuarto, están localizados en Cos. Knox (W. HEADLAM, D. KNOX, The Mimes and Fragments, 1922), en cambio, sostiene el origen ateniense de Herondas, ya que el askoliasmos descripto en el mimo octavo era una costumbre esencialmente ática. 


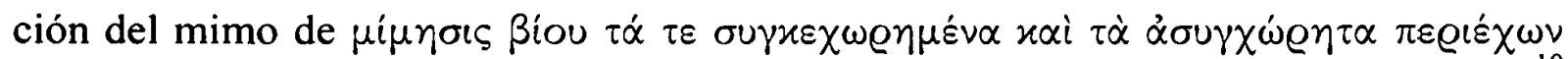
"imitación de la vida que involucra las cosas convenientes y las prohibidas", 10 definición que se aplica tanto al mimo popular como al literario, pues ambos se nutren de temas plebeyos acorde a los personajes que los encarnan, todos ellos vulgares," representantes del "proletariado urbano". 12 Pero el mimo cortesano de Herondas, exponente claro del filón "literario", agota el vívido realismo en el plano del contenido, ya que su forma, por contraposición, es artificial y literaria, habida cuenta del lenguaje y el metro utilizado. Efectivamente, la lengua del mimo herondeo es jónica en su ortografía y forma, ática en la sintaxis y con ciertos aderezos dóricos - así la detalla G. Arnott, ${ }^{13}$ aunque olvida sin embargo mencionar el uso de no pocos eolismos. Esta incongruencia entre el personaje y su lengua podría ser clave a los fines de la búsqueda de efectos humorísticos. Por otro lado, induce a considerar a Herondas un escritor de la elite, destinado a un público también letrado que pudiera reconocer el virtuosismo literario de su escritura refinada. Pero no es la lengua de los mimiambos el único rasgo de sofisticación helenística. Estos poemas dramáticos también pueden calificarse de arte allusiva, como las lecturas de la crítica más sutil de los últimos años vienen demostrando. ${ }^{14}$ Bajo la pseudo simplicidad de la superficie se descubre un artificio subyacente acorde con los patrones de escritura típicos de la época. ${ }^{15}$ Sería un error, entonces, considerar lisa y llanamente el mimo helenístico como una imitación 'fiel' de la vida doméstica, según creyó suponerse en un principio. ${ }^{16}$

Acorde con la sofisticación escrituraria que venimos señalando, la obra de Herondas alude a su propia artificiosidad en el seno de sí misma, exponiendo la fina conciencia del autor acerca de su oficio de escritor y las pretensiones de su particular poética. A propósito de esta característica, nos proponemos revisar la imagen del autor que surge del propio texto, menos en su calidad de autor implícito, es decir,

10 Definición preservada por Diomedes (fr. 61, Kaibel), pero que puede remontarse a Teofrasto, según A. FouNTOULAKIS, "Herondas 8.66-79: Generic Self-Consciousness and Artistic Claims in Herondas' Mimiambs", Mnemosyne 55 (2002), p. 301-319.

1 Cf. D. Konstan, "The tyrant Goddess: Herodas' Fifth Mime", ClAnt 8 (1989), p. 268: "They are, rather, characters on the margins of citizen society. I would suggest that their roles are perhaps better described by the figure of exclusion - as outsiders versus insiders - than by the figure of high and low, that is, as members of an inferior or poorer class."

12 CUNNINGHAM, o.c. (n. 6), p. 13.

13 W.G. ARNOTT, "Herodas and the Kitchen Sink", G\&R 18 (1971), p. 121-132.

14 Ver, por ejemplo, los agudos comentarios de J. STERN ("Herodas' Mimiamb 6", GRBS 20 [1979], p. 247-254; "Herodas' Mimiamb I", GRBS 22 [1981], p. 161-165; "Herodas' Mimiamb 5", CPh 76 [1981], p. 207-211) o E. EsPosıTo ("Allusività epica e ispirazione giambica in Herond. 1 e 8", Eikasmos 12 [2001], p. 141-159).

15 Cf. J. STERN, "Herodas, Theocritus and the Urban Mime", Actas del XIII Simposio Nacional de Estudios Clásicos, La Plata, 1997, p. 30: "This is what we might call bookish literature -literature of the academy, intended - I think Mastromarco is correct here - for live performance before small, elite audiences capable of appreciating the allusive aspects of the texts."

16 El apogeo de la estética del realismo en variados campos del quehacer artístico por los años en que Herondas salía a la luz (finales del siglo XIX) debió de ejercer no poca influencia a la hora de considerarlo un realista. 
inscripto en la misma enunciación del texto, como en calidad de personaje dentro de las piezas, ficcionalizado él mismo o transpuesta su figura en otros personajes. Nos interesa determinar la posición desde la cual nos habla el poeta, cuáles son sus deudas respecto al pasado y de qué forma está involucrado en su presente. Es decir, cómo construye su voz a partir de la tradición literaria y en confrontación con sus contemporáneos. ${ }^{17}$ Pero, como los autores también producen lectores, evaluaremos de qué modo controla el autor esta relación compleja con su público, sus expectativas y pretensiones de cómo debe ser leído. En todos los casos se trata de una construcción poética acerca del autor y su público, y por tanto no pueden estas consideraciones aplicarse sin más al autor y receptor histórico. De todos modos, y aun con estos reparos, quizá puedan echar luz sobre cuestiones empíricas de la creación y la recepción de los mimos. ${ }^{18}$

Para estas cuestiones, parece inevitable comenzar por el mimo octavo, un breve manifiesto literario, recompuesto a partir de fragmentos identificados y reintegrados gracias a la valiosa tarea del británico Knox. ${ }^{19}$ El arduo trabajo dejó al descubierto un ejemplo más de Dichterweihe, fórmula favorita de los poetas helenísticos, profundamente enraizada en la tradición literaria griega, en la que por regla general el encuentro con un dios tiene como finalidad la instrucción del poeta. Recordemos el sueño de Esquilo, según la anécdota de Pausanias $(I, 21,2)$, en el que Dioniso le ordena escribir tragedias, o el testimonio de Calímaco, que también registra la revelación de su consagración poética a través de un sueño (Aitia). Sólo que en Herondas la anécdota alcanza un desarrollo mucho más extenso. En efecto, el relato de su contenido se sucede como narración sostenida a lo largo de 50 versos claramente enmarcados. ${ }^{20}$ Tanto en el marco como en el sueño, estratégicamente el autor se confiere a sí mismo el status del protagonista. ${ }^{21}$

17 Cf. S. Goldhill, The Poet's Voice, Cambridge, 1991. Dedica a Teócrito el capítulo que versa sobre autores helenísticos; muchos de sus comentarios, empero, se aplican a todos los poetas cortesanos.

18 Cf. J. LightFOOT, "Sophisticates and Solecisms: Greek Literature after the Classical Period", en O. TAPLIN (ed.), Literature in the Greek World, Oxford, 2000, p. 221: "(...) it is a mistake to infer biographical details from an author's work in any over-simple way, it can be no less so to try to reconstruct his milieu from his own heavily loaded account of it."

19 El mimo octavo, por su carácter programático, podría constituir, según G. LAWALL, "Herodas 6 and 7 reconsidered", $C P h 71$ (1976), p. 165-169, el final de un libro de ocho mimiambos. A. RIST, "A Fresh Look at Herodas' Bucolic Masquerade", Phoenix 51 (1997), p. 354-363, en cambio, considera más probable la posibilidad de que fuera el prólogo de un segundo libro de poemas dramáticos, en donde el autor refuta la crítica que generó el primero de sus volúmenes.

20 La preponderancia de lo narrativo sobre lo dramático, amén de la forma monológica, hacen del mimo octavo un caso particular dentro del conjunto breve de obras del autor.

21 Algunos pocos filólogos (entre otros, Vogliano, Terzaghi y Veneroni) sostienen que quien narra el sueño a una esclava es más bien un personaje femenino. La hipótesis se funda, principalmente, en el contexto mismo de la situación; las mujeres, por ejemplo, serían más proclives a las supersticiones oníricas. Les resulta difícil, sin embargo, desconocer la efectiva voz del poeta a partir del v. 65, en lo que es la exégesis del sueño. Para Vogliano la situación se explica si, como ha sugerido Wilamowitz, el propio poeta fuera el que recitara bajo la máscara 
En la primera de estas instancias (1-15 principalmente), el autor-personaje, o, si se prefiere, el alter ego del autor, ${ }^{22}$ queda inserto en el ambiente doméstico característico del mimo. El nivel de vida representado no puede ser más cotidiano. Las preocupaciones del personaje se concentran en asuntos triviales, como la necesidad de calmar la sed de la cerda (2) o la falta de lana para fabricar una guirnalda (1213), del mismo modo que, en el mimo sexto, por ejemplo, una de las protagonistas dirige su atención a la alimentación de las gallinas (100-101). Dentro del hogar, el poeta juega su rol de patrón y pena por la pereza de sus esclavos, situación también recurrente en los mimiambos al punto de conformarse en una escena típica del género. El enfrentamiento más o menos virulento entre amo y servidor es totalmente irrelevante en el plano de la acción dramática, pero parecería definitivamente imprescindible para la preceptiva poética del mimo. La violencia del amo, en este caso, es tanto física - amenaza con ablandar la cabeza de una esclava (9) - como verbal. Sus obsesiones, lo mismo que el lenguaje que las expresa, no hacen sino ingresarlo en el mundillo ordinario de la indecente sociedad del mimo. Nos interesa destacar el modo ambiguo en que Herondas se da vida literaria a sí mismo, porque, si bien repite los atributos de la mayoría de sus criaturas, mimetizándose con ellas y eliminando cualquier tipo de distanciamiento irónico esperable dada la situación de superioridad que le confiere su oficio de creador-poeta, por otro lado, se arroga para sí mismo el papel del amo, y evita cualquier situación de confrontación con otros personajes que puedan resultar sus pares. Se encuentra en escena acompañado nomás por sus servidoras.

Precisamente a una de ellas, Aná, el poeta narra el desarrollo de su sueño. El estado deplorable del papiro, no lo deja leer en su totalidad. Sabemos que en la escena inaugural Herondas arrastra una cabra a través de un despenadero (16-17), la misma que unos cabreros escogen como víctima para ser inmediatamente despedazada. Cerca de él hace su aparición una figura naturalmente identificada con Dioniso en razón de los atributos de su vestimenta: túnica azafranada, estola de ciervo moteado, corona de hiedra, coturnos (26-33). La laguna textual que sigue a esta descripción es insalvable y el texto vuelve a hacerse legible cuando el autor ya se encuentra involucrado en la ceremonia del askoliasmos, cuya prueba consistía en mantenerse erguido saltando encima de un odre repleto de aire, un concurso en honor a Dioniso (40-47). ${ }^{23}$ El autor vence en la competencia, aunque un viejo lo amenaza con su bastón (58-61). El

de la mujer, máscara que finalmente se quita. Fantasea incluso con que Herodas pudiera haber sido en realidad una poetisa, Herodiade. Ver A. Vogliano, "Nuovi studi sui Mimiambi di Heroda", RFIC 53 (1925), p. 395-412. Nosotros entendemos que en el mimo octavo habla un solo personaje, al mismo tiempo narrador en el exordio y protagonista del sueño. Ese personaje nos remite a Herondas, lo que nos compele a sostener que el mismo Herondas, entonces, sueñe, cuente el sueño y lo interprete.

22 Así lo llama C. Miralles, "La poetica di Eroda", Aevum Antiquum 5 (1992), p. 89-113.

23 El askoliasmos formaba parte de la Dionisia rural y su nombre sugiere el salto en una o ambas piernas. Las Dionisias rurales podrian haber tenido conexión con el origen del teatro, dato que estaría vinculado con el significado de Dioniso en el sueño. Sobre el askoliasmos, ver H.W. PARKe, Festivals of the Athenians, Ithaka (NY), 1977, p. 102. En el sueño se alude también a rituales dionisíacos en el sparagmos y la omophagia de la cabra. 
hecho, sin embargo, no llega a empañar la algarabía del triunfo porque inmediatamente se pone como testigo a un joven que otorgará a ambos el premio (64).

El propio Herondas se ofrece como exegeta del sueño y de ese modo reingresamos imprevistamente en el marco (65). En la clave interpretativa que el autor nos brinda, la cabra representa la señal de que obtendrá algún regalo de parte de Dioniso (67-68). Los cabreros que desgarran al animal son "los muchos 'interesados' en las

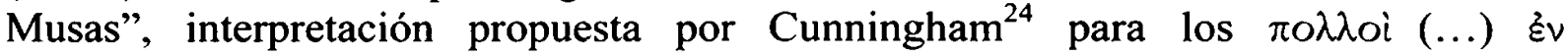
Moúonı denominar a "la gente del Museo", es decir la intelligentsia de la época, estudiosos y críticos de las nuevas instituciones culturales alejandrinas. ${ }^{25}$ Es manifiesto, entonces, que la cabra pasa a ser su producción poética - el presente dionisíaco, - una representación alegórica que le permite a Herondas jugar con los significados del término

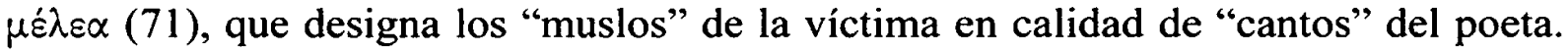
El mimo se cierra con la sugerencia de que la obtención del premio es índice de que alcanzará una gran gloria a partir de los yambos (77), o bien que se le asigna la tarea de cantar coliambos, luego de Hiponacte, a los jonios venideros (78). ${ }^{26}$ La referencia a Hiponacte, de quien el poeta se declara su sucesor, responde a la obsesión de los alejandrinos por los textos y autores del pasado, a los que suelen mirar con respeto pero manipular con desenfado. No hay lugar a dudas de que la estrategia retórica de la totalidad del poema está al servicio del autoelogio del escritor.

No nos detendremos en el hecho mismo del sueño a través del cual no pocos poetas fueron aleccionados sobre su métier poético o les han sido señaladas sus raíces literarias. El tema ha sido ya transitado por la crítica. Se trata de un topos literario que cumple la función de legitimar un sitial poético siempre elevado que recubre de autoridad al autor y sus poemas ${ }^{27}$ y revela, al mismo tiempo, la conciencia del autor acerca de la posición que quiere ocupar dentro de la tradición poética. Bien ha descripto esta situación Goldhill: ${ }^{28}$

In the Hellenistic era, to write as a poet and with a self-conscious affiliation to a tradition of poetic sophia necessarily involves negotiating a problematized conception

24 CUNNINGHAM, o.c (n. 6), p. 202.

25 R.M. Rosen, "Mixing of Genres and Literary Program in Herodas 8", HSPh 94 (1992),

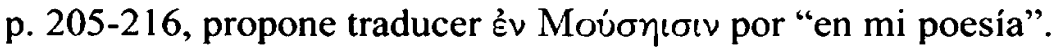

26 La distinción entre coliambos y yambos no deja de perturbar a la crítica. Rosen, l.c. (n. 25), interpreta que con ellos se hace alusión a la combinación de lo dramático (yambo) con el tradicional elemento hiponacteo (coliambos), mezcla que efectivamente manifiestan las composiciones de Herondas. Sobre las afinidades de Herondas con la obra de Hiponacte, ver especialmente R.G. UsSHER, "The Mimiamboi of Herodas", Hermathena 129 (1980), p. 65-76, y el exhaustivo estudio de E. DEGANI, "Ipponatte e i poeti filologi", Aevum Antiquum 8 (1995), p. $105-136$.

27 Fountoulakis, l.c. (n. 10). Cf., entre otros ejemplos, el sueño de Ennio en Anales, en el que Homero se le aparece, o el "Idilio 7" de Teócrito, en el que Simíquidas recibe la instrucción poética a través de las ninfas. Según T.L.B. WEBSTER, Hellenistic Poetry and Art, London, 1966, el sueño de Herondas sería una variación de la iniciación poética de Arquíloco.

28 O.c. (n. 17), p. 225. 
of intellectual, social and literary authority -as it involves the complex task of selfrepresentation within such contests of authorization.

Haremos hincapié, en cambio, en el tipo de información que el relato onírico puede brindarnos acerca de la relación del autor con su obra, información que alude al proceso de la creación literaria.

Que la ceremonia festiva en la que culmina la narrativa del sueño precisamente se dé en un contexto dionisíaco, así como la presencia previa del propio Dioniso, parecen aunarse para poner de relevancia el papel de esta divinidad con respecto a la profesión del poeta. Sobre esta evidencia hubo quienes interpretaron que con ello se certificaba el carácter performativo del mimo, en oposición a quienes sostenían el carácter meramente libresco de la poesía de Herondas. Sin embargo, es dable observar que Dioniso, si bien el dios del teatro, es también el dios del simposio, por lo que su presencia no puede ser una prueba contundente del carácter dramático de los mimos. Por otro lado, y quizá no menos importante, no debemos olvidar que Dioniso era el dios de los nuevos reyes macedónicos de Egipto, a quienes el mismo Herondas ensalza en el mimo I (30). No cabrían dudas de que su encuentro implica el respaldo de la divinidad en la legitimación del autor.

La primera semblanza que se ofrece del escritor es aquella que lo describe arrastrando una cabra, cuya destacada apariencia se deja leer en la mención de su "linda barba" ( $\varepsilon \dot{u} \pi \omega \dot{\omega}[\gamma \omega \nu], 17)$ y sus "lindos cuernos" ( $\varepsilon u ̉ \varkappa \varepsilon \varrho \omega \varsigma, 17)$. La repetición del prefijo عủ, en ambos adjetivos, soporta lexicalmente la noción de belleza aplicada a la cabra, obviamente signo de la perfección de la obra que vale como una calificación inscripta en la propia composición. ${ }^{29}$ Es un juicio de valor en el que la calidad se mide en términos estéticos, méritos que en virtud de la alegoría deben ser trasladados a la obra de Herondas, lo que puede resultar un tanto paradójico a juzgar por la sordidez de los temas o los personajes que retrata. Por otro lado, destacamos la situación del autor, guía y conductor del animal, para nosotros un símbolo de que se considera en pleno control de su creación artística, aunque el camino por donde lo conduce es

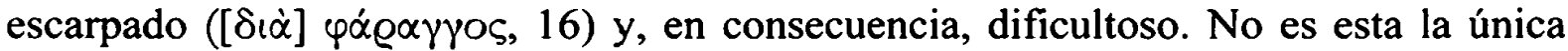
señal de que el esfuerzo caracteriza la tarea del escritor, porque unas líneas más adelante las composiciones del autor, que reciben variadas denominaciones en este breve poema, serán designadas con el término $\mu$ ó $\chi$ Oous (71), que ciertamente implica una labor trabajosa. ${ }^{30}$ Adhiriendo a esta concepción que aúna esfuerzo con creatividad literaria, Herondas se muestra cercano a los principios poéticos de los autores helenísticos que cifran en el ponos la dimensión de su labor como escritores. ${ }^{31}$

29 Según Rist, l.c. (n.19), los adjetivos aluden a la delicadeza de su condición, tal como se requería efectivamente que fuera el ejemplar escogido como víctima de un sacrificio.

30 En la misma dirección, B. VENERONI, "Ricerche su due Mimiambi di Eroda", RIL 105 (1971), p. 226, interpreta que la conducción de la cabra es simbólica del logro poético de Herondas.

31 Cf. Teócrito, Idilio 7 , también un escrito programático, donde Lícidas utiliza el verbo ekponeo para aludir a la creación poética (v. 51). Al respecto comenta GoLDHILL, o.c. (n. 17), p. 233: "The careful activity of the poet rather than the immediated inspiration of the Muses." 
La escena siguiente, la del askoliasmos en el que participa triunfalmente el autor, vuelve a centrarse alegóricamente en la cuestión del proceso escriturario. El episodio aúna varias circunstancias ilustrativas del tema. No sólo porque el autor se vea inmerso en la competencia - y ésta debería entenderse como una competencia entre pares - sino también porque el odre sobre el que se salta bien podría estar fabricado a partir de las vísceras de la misma cabra, según sugiere Rosen. ${ }^{32}$ La ceremonia consistía en saltar - ¿con un solo pie? - sin caerse, lo que representaría una fidedigna imagen de lo que efectivamente hacía Herondas, cantar versos rengos ( $\tau] \dot{\alpha} \varkappa u ́ \lambda \lambda$ ' $\dot{\alpha} \varepsilon i \delta \varepsilon \imath \nu, 79)$, como se expone al concluir el poema, no otra cosa que componer en coliambos, como lo hizo también su contemporáneo Calímaco, e Hiponacte en épocas pasadas. La competencia es emblemática de la destreza poética de Herondas, que se patentiza en la capacidad de superar a sus adversarios saltando dos veces, cuando ellos, de cabeza o de espaldas, con violencia caían al suelo (41-43). ${ }^{33}$

Sin embargo, no todas son glorias. Porque las instancias de recepción que ilustra el mimo octavo, es decir, las imágenes de la relación obra-público, en su conjunto no pueden tildarse de armónicas. Es éste el otro aspecto en el que nos interesa detenernos en nuestro desarrollo. El mimo octavo refiere el contacto de diferentes actores sociales con la poesía de Herondas. Siguiendo el orden del drama, en primer lugar, el despedazamiento de la cabra por parte de unos cabreros ( $\alpha i] \pi o ́ \lambda o l, 69)$ en cumplimiento de ritos divinos, según ya hemos sucintamente comentado en el resumen del sueño. Recordemos que estos cabreros podrían ser tanto los poetas alejandrinos como los críticos que la industria paraliteraria helenística supo generar. Ni siquiera tendría que escogerse entre uno y otro grupo, ya que los mismos estudiosos de la literatura eran las más de las veces autores literarios. Nos resulta muy dificultoso identificarlos con certeza, aunque no faltaron las propuestas en tal sentido. Para Webster (1967), ${ }^{34}$ entre otros, representan la escuela de Cos, Teócrito y sus amigos; y ciertamente la apariencia de cabreros podría considerarse un guiño al respecto. Para Smotrytsch, ${ }^{35}$ en cambio, no serían otros que los technitai de Dioniso, quienes enérgicamente rechazaban el ingreso del mimógrafo en el seno de la hermandad. A nuestro modo de ver, este público "destructor" de la obra de Herondas pone de relieve una polémica literaria generada en el milieu erudito de la corte o la Biblioteca. Coincidimos con Veneroni ${ }^{36}$ en considerar que la escena simboliza la incomprensión, por parte de los poetas doctos, de la obra de Herondas. El debate podría fundarse, y en nuestra hipótesis no somos originales, en la curiosa amalgama que ostenta la factura del mimo, entre una forma preciosista y refinada, nada objetable en ese ambiente

32 ROSEN, l.c. (n. 25).

33 MiRalles, l.c. (n. 22), identifica a estos adversarios con los otros poetas que también habían adoptado el coliambo en sus poesías.

34 WEBSTER, o.c. (n. 27), p. 97: "What he claims in the dream is that he has defeated the pastoral poets of Kos with another and equally artificial kind of mime -themes from comedy transmuted into sketches written in the Old Ionic of Hipponax."

35 A.P. SMOTRYTSCH, "Eronda e il vecchio", Helikon 2 (1962), p. 613.

36 VENERONI, l.c. (n. 30). 
libresco, y un contenido sórdido y vulgar, herencia de un género popular menor y despreciado por la elite. ${ }^{37}$

No es esta, empero, la única instancia de recepción negativa dentro del mimo VIII. A este menosprecio de la crítica, como damos en suponer, se suma la situación de la competencia del askoliasmos, que hemos interpretado como una figuración del acto creativo para recalcar la maestría del poeta. Sabemos que el resultado ha sido reñido: un viejo reclama la victoria para sí despojando al poeta del reconocimiento que merecía a juzgar por su hábil participación. No nos explayaremos en las variadas posibilidades de otorgar un nombre propio al personaje del anciano. ${ }^{38}$ Aceptamos, aunque con reservas, la idea mayoritaria de que representa al yambógrafo Hiponacte, ${ }^{39}$ cuya reacción violenta también puede adjudicarse a variadas motivaciones. ${ }^{40}$ No encontramos razones más convincentes para sostener otra propuesta. El askoliasmos tiene en el joven allí presente un árbitro que proclama la victoria de ambos contrincantes. Suponer que ese joven no es otro que Dioniso -recordemos que el dios también es un joven en Bacantes -, induce a pensar en una consagración que proviene de la propia divinidad, lo que constituye al mismo tiempo una calificada desca-

37 En la misma dirección, EsPosito, l.c. (n. 14), observa una clara voluntad de inversión en Herondas, una degradación de los valores de la tradición áulica y del epos heroico, lo que le hace prever al propio autor una polémica literaria.

38 Desde el nombre de Teócrito o Filetas como propuso Herzog, o Calímaco, un adversario histórico del Herondas real, como propuso Knox. SMOTRYTSCH, l.c. (n. 34), desarrolla la teoría de Knox sobre la hipótesis de un enfrentamiento entre dos corrientes artísticas en el período helenístico ( $\mathrm{C}$. Yambo I y XIII de Calimaco) que la escena estaría reflejando. A esta misma contienda haría alusión la defensa de Apeles en el mimo cuarto. La disputa con Calímaco tendría su origen en que ambos escribieron coliambos, y la polémica también involucraría a Leónidas de Taranto, afín a Herondas en contenido y estilo. Más recientemente RisT, l.c. (n. 19), identificó al viejo con Arquíloco, en consonancia con los versos finales del poema, que harían referencia a Arquíloco e Hiponacte respectivamente, en la oposición yambos-coliambos.

39 El primero en identificarlo con Hiponacte fue Vogliano. Varias razones han sostenido esta hipótesis: Herondas se autoproclama su heredero (78-79), su apariencia de anciano, como en Alceo, y la reacción violenta que reflejaría la proverbial ira hiponactea. No solo esta, sino todas las escenas de golpes, ya con puño o garrote, podrían considerarse una referencia a Hiponacte según MiRALLES, l.c. (n. 22). La situación tendría sus orígenes en el pasaje homérico en que Odiseo e Iro se enfrentan, efectivamente uno de los intertextos del mimo VIII.

40 Rosen, l.c. (n. 25), por ejemplo, supone que la contienda se debe a la adulteración que, según la percepción de Hiponacte, Herondas ha cometido con su propio tipo de arte al mezclarlo con el drama. FountoulaKIS, l.c. (n. 10), p. 309, objeta la suposición de Rosen, y propone justificar la ira del viejo solo si entendemos que esa mezcla alude muy especialmente al mimo no literario, al que juzga menos prestigioso y más improvisado: “(...) the non-literary mime was, in the first half of the third century B.C., when Herondas must have composed his poems, still considered as a low-life, often indecent, spectacle dominated by short and simple plots centred on everyday incidents and ordinary lower-class characters, easy laughter and improvisation." Cabrían muy pocas dudas de que la producción herondea representa un producto novedoso y la combinación de estilos y géneros pudo ser considerada como inapropiada. Por otro lado, no habría nada de extraño en considerar a un imitador al mismo tiempo como rival (al respecto ver N. HuTCHINSON, Hellenistic Poetry, Oxford, p. 237, n. 47). 
lificación de la actitud de los colegas victimarios. ${ }^{41}$ La salomónica solución del jovendios proclama el reconocimiento del valor literario de la poesía de Herondas desde la perspectiva del lector experto, encarnado en la figura de quien debe hacer de juez en la disputa - Dioniso ya ha ejercido como juez en Ranas de Aristófanes - un ejemplo de recepción abiertamente contraria a la de los críticos que previamente despedazaron su obra, también ellos eruditos. No obstante, la sanción de una situación de equidad entre Herondas y el viejo parece no satisfacerle del todo al primero, porque en el verso 73 el autor afirma que él solo ( $\mu$ ouvos) creía merecer la victoria. Ello nos mueve a determinar que en los dos casos hasta ahora comentados nos encontramos ante situaciones de respuestas del público no deseadas. $O$ bien porque la obra es despedaza y destruida por una crítica que no la comprende con justeza, o bien porque no se la juzga en toda su superioridad. Ambos son casos de recepción a cargo de gente de la elite. Ejemplos llamativamente curiosos, por cierto, en una obrita donde la finalidad parece centrarse en la defensa de los cánones artísticos del autor, a no ser que efectivamente la oposición a Herondas en el ambiente literato fuera pública y masiva y el objetivo de este mimo apuntara más bien a repudiarla por inmerecida. Vale decir que este ataque habría determinado la génesis del poema e impulsado a Herondas a la resistencia en un arte que él consideraba digno de elogios.

Sin embargo, opuesta a la incomprensión de estos cultos receptores, encontramos, en la misma pieza, la reacción colectiva del público espectador del askoliasmos. Designado con la vaga referencia de "los hombres" ( $\omega \nu \theta \varrho \omega \pi[o t], 46)$, testigos presenciales del evento ritual, creemos identificar en ellos una audiencia de tipo popular dentro del texto. Recordemos que el askoliasmos era una festividad campesina, que involucraba inclusive a los estratos sociales más bajos de la población, incluyendo a los esclavos. La respuesta emocional de esta gente da muestras del reconocimiento público hacia el poeta, cifrado en el grito de admiración pronunciado cuando lo "vieron comprimiendo la piel" (47). ${ }^{42}$

Hasta aquí en lo que respecta al asunto del sueño. Pero recordemos que todo él es de por sí una sostenida narración relatada también a un público oyente. Estamos aludiendo al caso de la esclava Aná a quien Herondas cuenta el sueño, destinataria especialmente escogida entre sus pares por no tener "pensamientos infantiles" (15), lo que no alcanza para calificarla de inteligente, pero sí probablemente de menos ingenua. En esta circunstancia el receptor escucha de boca del propio autor no otra cosa que lo que efectivamente será parte de uno de sus mimos. Se trata de un caso de recepción interna, que está lejos de ilustrar la lectura del público erudito que generalmente se inscribe como espectador modelo o implícito de la escritura culta de Herondas, según ya hemos previamente señalado. Uno esperaría que a la interlocutora especialmente escogida para la ocasión se le cediera la posición de exegeta del sueño. Sin embargo el poeta no relega este papel en ningún otro más que en sí mismo. El

41 Scgún Crusius, el joven sería Ptolomeo. De la misma opinión también SMOTRYTSCH, l.c. (n. 35), p. 605: "allegoricamente una gara poetica per la festa di Dioniso ad Alessandria, dove, come giudoce dei poeti, interviene lo stesso re."

42 VENERONI, l.c. (n. 30), y ROSEN, l.c. (n. 25), asocian el askoliasmos con una competencia dramática, aunque Rosen previene de que el hecho de que hubiera público no debe tomarse como prueba del carácter performativo de la poesía de Herondas. 
gesto no hace sino reafirmar la distancia patronal frente a su esclava. Pero, ¿para qué se la convocó si termina despojada de toda palabra? Sin duda puede disfrutar de la audición del relato del sueño, aunque la hermenéutica del mismo es cosa de avezados, según se deduce del comportamiento del poeta, quien ratifica en forma implícita con su exégesis la autoridad y competencia para ejercerla. En el ejercicio de esa autoridad profesa un control tiránico de su lectura.

Pero no es el mimo octavo, en su carácter de manifiesto poético, el único que tematiza la relación vinculante entre la tríada autor, obra y público, de un modo que pueda interpretarse como una autorreflexión sobre la situación del poeta y la manera cómo los lectores deberían relacionarse con el texto. En el mimo cuarto, "Las mujeres que hacen ofrendas y sacrificios a Asclepio", Cino y File arriban al templo del dios, probablemente en $\operatorname{Cos},{ }^{43}$ para ofrecer la humilde dádiva de un gallo en agradecimiento a los beneficios que éste les ha otorgado. ${ }^{44} \mathrm{La}$ ocasión es propicia - la avala una larga tradición al respecto- ${ }^{45}$ para que el pequeño drama se concentre en la mirada atónita de una de las visitantes, quien, con cierta ingenuidad, juzga la belleza de las obras de arte presentes en el lugar, en su mayoría como ofrendas votivas: $\tilde{\alpha}, x \alpha \lambda \tilde{\omega} \nu$,

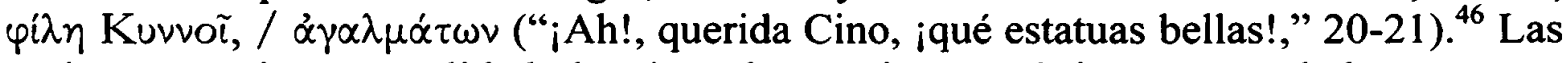
mujeres aprecian, en realidad, dos tipos de creaciones artísticas. Por un lado, un grupo de estatuas situadas en las afueras del templo y, por otro, las pinturas de Apeles en el interior del mismo. ${ }^{47} \mathrm{La}$ alabanza destaca la fidedigna reproducción de la realidad de

43 Ofrece reparos a esta propuesta CUNNINGHAM, o.c. (n. 6), pues las obras de arte descriptas dentro del templo no se conocen en referencia a Cos.

44 Ha sido una cuestión debatida por la crítica la atribución de los versos a los personajes del drama. No hay consenso tampoco acerca de su número. Optamos por la propuesta de CunNINGHAM, o.c. (n. 6). Para una visión distinta, ver W.G. ARNOTT, "The Women in Herodas, Mimiamb 4", CL 4 (1984), p. 10-12.

45 La situación de ekphrasis en lugares de culto puede remontarse a $\theta \varepsilon \alpha \varrho o i ́$ de Epicarmo,

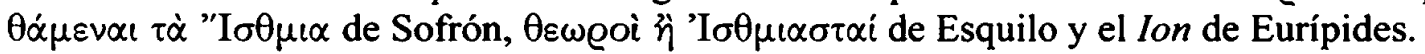

46 Dejaremos de lado las similitudes entre el mimo en cuestión y el Idilio XV de Teócrito, en el que unas siracusanas comentan sobre obras de arte en el contexto del festival de Adonis en la Alejandría de los Ptolomeos. Al respecto ver los agudos estudios de S. GolDHILL, "The naive and the Knowing Eye: Ecphrasis and the Culture of Viewing in the Hellenistic World", en S. Goldhill, R. OsBorne (eds.), Art and Text in Ancient Greek Culture, Cambridge, 1994, p. 197-223; J. BURTON, "Ekphrasis and the Reception of Works of Art", en Theocritus's Urban Mimes: Mobility, Gender, and Patronage, Berkeley, 1995, p. 93-122; y M.B. SKINNER, "Ladies' Day at the Art Institute. Theocritus, Herodas, and the Gendered Gaze", en A. LARDINOIS, L. MCCLURE (eds.), Making Silence Speak. Women's Voices in Greek Literature and Society, Princeton/Oxford, 2001, p. 201-222.

47 Con respecto a las estatuas, G. ZANKER, "Poetry and Art in Herodas, Mimiamb 4", Seventh Groningen Workshop on Hellenistic Poetry. Beyond the Canon, Groningen, 2004, p. 297-314, opina que las primeras se corresponden con imágenes de las divinidades en el altar, las siguientes, en cambio, efectivamente representan ofrendas votivas y se encuentran en la pronaos. Se trata de un grupo realizado por los hijos de Praxíteles: una niña mirando una manzana, un viejo, un niño con una oca, la imagen de una tal Bátale. La pintura de Apeles representa un sacrificio. STERN, l.c. (n. 15) cree notar una sutil diferencia entre el realismo 


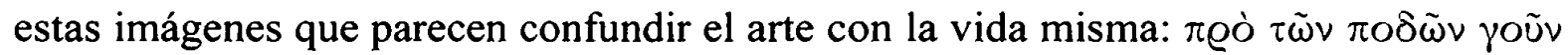

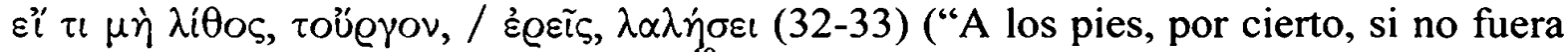
piedra, diría que la obra va a hablar"). ${ }^{48}$

Difícil no equiparar la situación de las mujeres de cara a estas creaciones artísticas con una puesta en abismo: ${ }^{49}$ ellas mismas, creación realista de otro artista, Herondas, expuestas a admirar lo que no es sino una cualidad de su propia factura. A decir verdad, como bien ha señalado Elsner, ${ }^{50}$ toda instancia de ekphrasis donde se dramatiza un punto de vista conlleva una potencial autorreferencialidad que apunta al espectador empírico de la pieza, así como cualquier descripción de una obra de arte, como la de estas señoras en el mimo herondeo, tiene posibilidades de operar como metatexto sobre la propia naturaleza de la obra en la que está inserta. ${ }^{51}$ Inevitablemente la ekphrasis trae a cuento preocupaciones que tienen que ver con cuestiones de la creación artística como la ilusión, la mirada, la interpretación, el artificio, la representación. En nuestro caso, se le pide al lector/espectador que mire los objetos descriptos desde los ojos de unas mujeres rústicas, lo que inevitablemente produce un distanciamiento irónico, pues estas focalizadoras textualmente construidas se convierten en objeto de burla para un presupuesto receptor instruido y erudito, cómplice del autor. La situación se provoca tanto a partir de las declaraciones de la que experimenta por vez primera el encuentro con las piezas de arte (File), como de la que se considera más culta (Cino). Nos referimos a expresiones inadecuadas como la

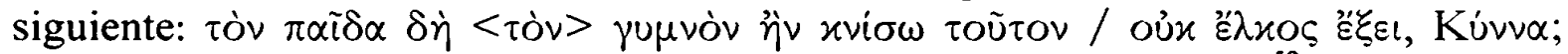
(59-60) (“Al niño desnudo, si lo araño, ¿no lo voy a lastimar, Cino?").

atribuido a las estatuas y el atribuido a las pinturas. Ambas son descriptas como verdaderas con respecto a la vida, pero la pintura parece interactuar con los ojos que la ven.

48 El realismo se define regularmente como el deseo de llevar la literatura hacia el contacto más cercano posible con la experiencia sensorial, intelectual y emocional. Se percibe esencialmente en la insistencia en los detalles, en lo familiar, en los trazos observables del mundo. G. ZANKER, Realism in Alexandrian Poetry: A Literature and Its Audience, London, 1987, explica el realismo alejandrino principalmente como una respuesta a la crisis de identidad cultural de las nuevas ciudades helenísticas, sobre todo en el seno de su población educada. El ejemplo extremo de realismo artístico, entre los objetos comentados por el mimo sexto, sin duda es el de la estatua de Bátale que vuelve innecesario ver el modelo para conocerla (35-38).

49 "Mise en abîme" es una expresión acuñada por A. Gide a partir de la heráldica y ha sido usada por el mismo autor y la crítica posterior de manera amplia para explicar "todo enclave que guarde relación de similitud con la obra que lo contiene" (L. DÄLlENBACH, El relato especular, Madrid, 1991, p. 16).

50 J. ElSNER, "Introduction: The Genres of Ekphrasis", Ramus 31 (2004), p. 1-18.

51 " (...) there are particular qualities of self-referenciality, mirroring and mise-en-abime, that may inevitably come into play when a work of literary art, such a long poem, novel or speech, turns to the description of a work of plastic or pictorial art such as a sculpture, textile or painting" (ELSNER, l.c. [n. 50], p. 3).

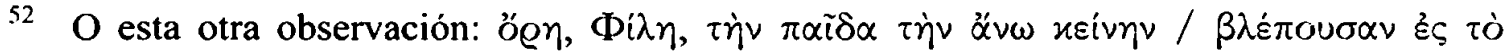

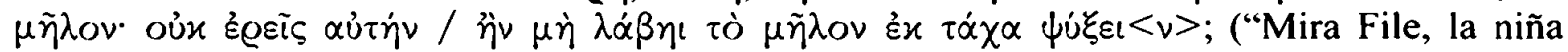
aquella que eleva la vista hacia la manzana. ¿No dirías que, si no toma la manzana, se va a desmayar?", v. 27-29). BURTON, l.c. (n. 46), p. 99-100, carga las tintas sobre la imperfección de la mirada crítica de File (Kokkale en la edición que ha escogido) y llama la atención sobre 
Aunque comentarios de este tipo destilen una innegable ingenuidad, imposible dejar de reconocer en ellos, aunque deformados y exagerados con propósitos probablemente humorísticos, criterios de evaluación estándares de la estética helenística vigente, testimoniados en una plétora de epigramas que exaltan el verismo del arte de la época, ${ }^{53}$ por lo que sería inadecuado desacreditarlos sin más solo por el tipo de personaje que lo transmite. ${ }^{54}$ En este sentido, ya Groeneboom ${ }^{55}$ había postulado que Herondas colocaba en boca de las mujeres su propia visión, y la mayoría de la crítica comparte esta opinión. Es por voluntad del autor que las mujeres reflejan una manera "profesional" de apreciar el arte. ${ }^{56}$ La estrategia tiene sus dejos narcisistas: por medio de sus personajes instaura criterios de evaluación estética que favorecen la valoración de su propia poesía. Para el lector-espectador empírico la situación se resuelve de manera incómoda. No puede acabadamente homologarse con los personajes del drama y sus reacciones, pues estos están lejos de la imagen de una potencial audiencia ideal, tanto por su status social como por su condición femenina. ${ }^{57}$

Reparemos también cómo la efectiva inclusión del nombre de los escultores inscripto en la base de las estatuas (23-24) constituye un emblema del modo en que el mimo alude a cuestiones de creación artística, incorporando la figura del autor al

ciertas obsesiones del personaje, como la desnudez del joven, o la violencia y hostilidad del buey, que ponen en evidencia su falta de interés por el carácter religioso de la pintura y la inadecuación de sus comentarios al contexto. Nos parece más adecuado considerar que la distorsión de sus apreciaciones son más bien casos de exageración - rasgos de sus status y psicología - y no de 'mala interpretación'.

53 En la Antologia Palatina pueden leerse más de una treintena de poemas que atestiguan y ensalzan el realismo de la vaca de Myron. Cf. Th. Gelzer, "Mimus und Kunsttheorie bei Herodas. Mimiambus 4", Catalepton. Festschrift für B. Wyss zum 80 Geburstag, Basel, 1985, p. 96-116. El autor revisa otros testimonios de la época, de tipo teórico, que juzgan la semejanza con la realidad como el valor más importante dentro del patrón estético de la época.

54 Como lo hace F. SIMON, "Ta kyll' aeidein": Interpretationem zu den Mimiamben des Herodas, Frankfurt am Main, 1991, por ejemplo. En su opinión el mimo IV no contiene ninguna crítica seria, pues no podemos esperar nada serio de mujeres $\tan$ bajas y $\tan$ proclives a expresiones intempestivas.

55 P. GroeneboOM, Les Mimiambes d'Hérondas I-IV, Gröningen, 1922.

56 R. HUNTER, "Plautus and Herodas", en L. BENZ (ed.), Plautus und die Tradition des Stegreifspiels, Tübingen, 1995, p. 156-157. GFI.7ER, l.c (n. 53), p. 114, defiende fervorosamente la hipótesis de que tras los comentarios de las mujeres se ocultan algunos de los temas preferidos de las discusiones teóricas acerca del arte helenístico: "Herondas gibt also in diesem Gespräch über Kunstwerke eine Theorie der bildenden Künste in nuce. Er stellt in der Form populärer Reaktionen und Kommentare dar, was von andern in der Form der Anekdote illustriert oder in theoretischer Begrifflichkeit begründet wurde. Verschiedene Komponenten seiner Darstellung lassen sich auch anderswo belegen. Die oben genannten Autoren waren gewiss ihm und seinen Lesern bekannt; aber eine direkte Abhängigkeit ist natürlich in keinem Falle zu erweisen."

57 SKINNER, l.c. (n. 46), postula que los alejandrinos no hicieron sino incorporar la visión femenina que autoras como Erinna, Anyte y Nossis habían instituido por medio de sus epigramas ecfrásticos. La fuente de este motivo literario de la cuestión genérica de la mirada las mujeres frente a objetos de arte - podría remontarse a Sofrón. 
repertorio de personajes del drama. La interdependencia entre el autor y la obra se pone sobre el tapete cuando las mujeres expresan la necesidad de saber sobre los

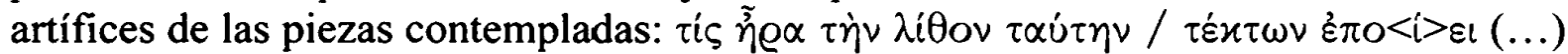
(“¿Qué escultor fabricó esta estatua [...]?", 21-22). Tanto los hijos de Praxíteles como Apeles reciben el elogio que se traslada, por la transposición que venimos señalando,

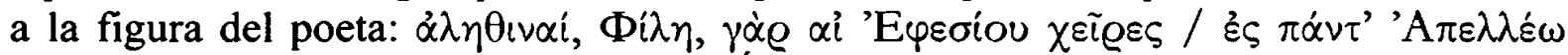
$\gamma \varrho \alpha ́ \mu \mu \alpha \tau^{\prime}$ (72-73) ("Las manos del de Éfeso, de Apeles, son verídicas en todas sus líneas"), dice una de las mujeres. ${ }^{58}$ De acuerdo con testimonios de Plinio, Apeles se había enfrentado a la corriente tradicionalista y conservadora del arte pictórico, escogiendo a cambio un tipo de arte verista que respondía al gusto del grueso del público. La factura misma de los personajes de los poemas de Herondas nos induce a pensar que nuestro poeta comulgaba con esta poética. ${ }^{59} \mathrm{Si}$ el pintor había soportado además la crítica de los otros colegas artistas, la defensa de Apeles puede leerse como una autodefensa. La discusión sobre la competencia de los receptores en virtud de sus conocimientos y estrato social estaba instalada entonces en el seno mismo de las percepciones críticas acerca de estas manifestaciones artísticas que imitaban la vida. Existe una tradición que afirma que Apeles consideraba como el mejor juez de sus obras a la gente del pueblo. ${ }^{60} \mathrm{La}$ admiración que suscita el arte realista en este tipo de público se manifiesta en las palabras de File que dan cuenta del grito emocionado - es nuestra traducción para $\alpha \dot{\nu} \eta \lambda \dot{\alpha} \lambda \alpha \xi^{\prime} \alpha^{\prime} \nu(70)$ - que soltaría, si ese gesto no fuese presuntuoso para una mujer (69-70). Destacamos que con igual término se describen las espontáneas manifestaciones de aprobación popular en el mimo octavo, cuando se narra la reacción física y el compromiso emocional que despertó el askoliasmos, no otra cosa que la creación poética de Herondas, entre los espectadores que admiraron su destreza: $x \dot{\eta} \lambda \alpha^{\prime} \lambda \alpha \xi_{\alpha \nu}, 46 .{ }^{61}$

En último término, ${ }^{62}$ incluiremos en nuestras observaciones atinentes a las cuestiones metaficcionales sobre la producción y la recepción artística en la mimografia herondea, los comentarios del mimo sexto, una pieza que expone una conversación privada entre dos amigas, Corito y Metró, acerca de las "virtudes" de un baubón, no otra cosa que un consolador fabricado en cuero, objeto de admiración de las

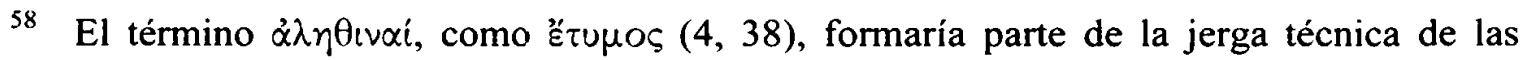
teorias de arte contemporáneo. Cf. GELZER, l.c. (n. 53), p. 103-104.

59 Luria fue el primero en postular la adhesión de Herondas, a través del comentario de sus personajes, al movimiento artístico representado por el pintor Apeles, en su obra y en su actividad como crítico. Ver al respecto O. SPECCHIA, "Gli Studi su eroda nell'ultimo trentennio", Cultura e scuola 70 (1979), p. 35.

60 ZANKER, o.c. (n. 48), p. 43.

61 El verbo designa normalmente un grito de guerra o se asocia con los sonidos de las bacantes inspiradas. En el contexto del mimo y aplicado por dos veces a una misma situación de contemplación "estética", creemos que más bien alude a un grito de aprobación o admiración frente a un tipo de manifestación artística conmovedora.

62 Estamos dejando de lado las referencias que a la propia ficción poética podrían leerse en el mimo I, según algunas propuestas de interpretación alegórica, como la de HuNTER, l.c. (n. 2). 
señoras. ${ }^{63}$ Lo primero que llama la atención es la naturaleza extravagante de los sentimientos generados por el objeto. Este dato precisamente nos parece la clave que habilita a una lectura menos literal y más sofisticada, sin perder tampoco de vista el efecto humorístico provocado a partir de la distancia entre el tipo de encomio y el objeto encomiado. Esa distancia tiñe de ironía todo tipo de comentario que sobre tal objeto se pronuncie. Otros mimos también han avalado lecturas desde variados frentes, no excluyentes entre sí. Es que efectivamente en el mimo sexto el consolador es celebrado como si se tratase de una obra de arte, con criterios estéticos y no exclusivamente funcionales: ¿qué pensar, si no, de su decoración con correítas o flecos de

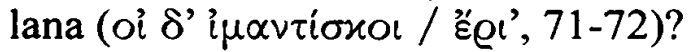

Stern fue el primero en proponer una lectura que emparentaba la apariencia del sórdido objeto con la obra del propio Herondas, y en los últimos tiempos esta lectura ha tenido cada vez más adeptos, a los cuales venimos a sumarnos. ${ }^{64}$ Nuestro aporte a una exégesis de este tipo reside en destacar algunos llamativos puntos de contacto entre el mimo en cuestión (VI) y el anteriormente comentado (IV), contactos que sin duda avalan la propuesta de entrever cuestiones de poética bajo comentarios de índole obscena. En primer lugar, la mención de Atenea, en uno y otro caso, como la virtual hacedora de objetos que revelan una calidad artística superior. En el mimo cuarto, al

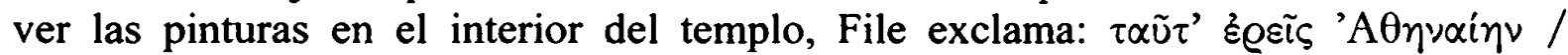

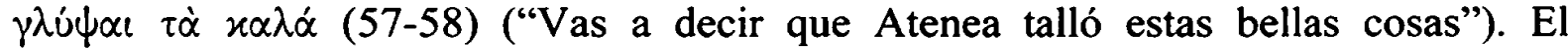
zapatero Cerdón, artífice de los consoladores en el mimo VI, también es comparado con la diosa Atenea, patrona de los artesanos. Reconoce Corito a su amiga Metró:

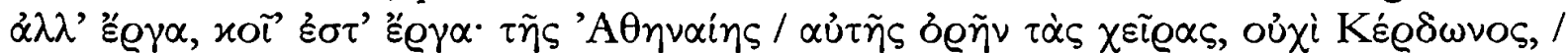
$\delta o ́ \xi \varepsilon ı s .(65-67)$ ("Pero sus trabajos, sus trabajos son tales, creerás ver las manos de la misma Atenea, no de Cerdón"). Como bien lo ha documentado Gelzer, la atribución

63 No es el único texto cómico que menciona un consolador en medio de una conversación entre mujeres. También aparece en Aristófanes: Lisistrata 107-110, 157-159, fr. 592 KA; Sofrón fr. $24 \mathrm{~K}$; Cratino fr. $354 \mathrm{KA}$; fr. $394 \mathrm{KA}$ y fr. 174, $18 \mathrm{~K}$ de Platón el cómico. El nombre atestiguado para designar el falo de cuero es ódı $\sigma \beta o \varsigma$. El término $\beta \alpha u \beta \omega \dot{\nu}$ podría catalogarse de hapax herondeo. S. SANTELIA, "Da Sofrone ad Eronda: tradizione di un motivo letterario", $C L 5$ (1989), p. 73-78, revisa cada uno de los pasajes mencionados y destaca la connotación negativa

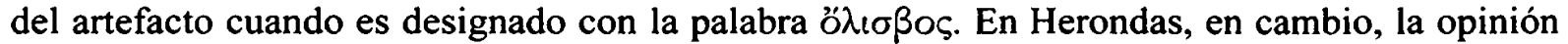
de las mujeres es positiva, lo que viene a destacar precisamente el carácter inusual de sus apreciaciones. Tibiletti Bruno (citado por SANTELIA, p. 77) explica etimológicamente las diferentes connotaciones de ambos términos. Hace derivar ö $\lambda \iota \sigma \beta o \varsigma$ de $\dot{\alpha} \lambda i \sigma \beta \eta$ y $\dot{\alpha} \lambda \dot{\alpha} O \mu \alpha \iota$, adjudicándole de este modo el sentido de "aquello que engaña"; en tanto $\beta \alpha u \beta \omega ́ v$, por su relación con $\beta \alpha \cup \beta \tilde{\alpha} \nu$ ("calmar", "adormecer"), adquiere un sentido positivo. Acorde con esta propuesta etimológica, Corito afirma que el consolador es "más dulce que el sueño" (v. 71).

64 STERN, l.c., 1979 (n. 14). Para este autor hay tres niveles posibles de lecturas del mimo VI: 1) el que alude a una realidad obscena, la interpretación literal de su narrativa; 2) el que esconde una burla del mito y del ritual órfico, lectura en clave cifrada en el léxico utilizado; y 3), el último, una declaración del autor sobre su propia poética. En este último nivel, el baubon reviste el carácter de emblema de la concepción poética de Herondas, finamente trabajado como el arte de Apeles. Cf. STERN, l.c. 1979 (n. 14), p. 253: "the wares of Kerdon, like those of Herodes, are grotesque on the surface but subtle and strangely beautiful beneath." 
de una obra de arte a alguna divinidad como un modo de alabanza no sólo es un recurso tradicional sino habitual para la época. ${ }^{65}$

En segundo lugar, llamamos la atención sobre el efecto que tanto las obras de arte como los consoladores producen en el público que los contempla: las pinturas por ser imágenes que confunden el arte con la vida; el baubon porque perfecciona la vida con arte. Nos estamos refiriendo a la excitación que provocan semejantes artefactos en sus espectadores, excitación que se trasluce en los ojos, sede de la mirada que los atrapa y los aprecia, ojos que urgen por salir de las órbitas. Cino, en el mimo IV, pregunta retóricamente si no se le escaparán las pupilas a Milo y Patecisco, nada menos que unos ladrones, cuando vean los objetos de plata pintados por Apeles

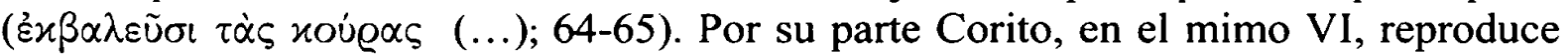
casi exactamente el mismo comentario acerca de quien contempla los baubones:

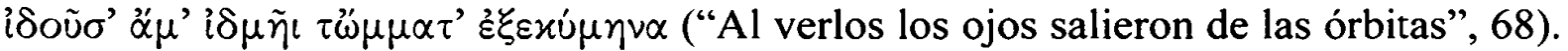
De modo que, así como las opiniones de las mujeres en el templo reproducían los criterios de valoración estética adecuados para juzgar la obra dramática de Herondas, de la misma manera las cualidades estéticas del consolador cifran los aspectos más destacados del mimo herondeo. Porque los consoladores, a la vista de las mujeres, resultan superiores a sus modelos reales, de los que obran como sustitutos (69). Ambos, el consolador y el mimo, imitan la vida real, pero, en su propia artificialidad pueden ser no solo bellos, recordemos la bella cabra del mimo VIII, sino mejores que sus modelos. En los personajes de Herondas hay ciertamente un nivel de alusión y virtuosismo lingüístico que revela más de lo que el personaje puede controlar, es ese plus el que también alcanza el baubon en su calidad de objeto artístico. En todos los casos, la belleza es el valor más preciado. El consolador es un "bello presente" (6. $21)$, también la cabra es un "presente de parte del bello Dioniso" (8.68), ni qué decir de las obras de arte expuestas en el templo de Asclepio $(4.20,26,39,58)$.

\section{Algunas conclusiones}

Sin duda la escritura refinada de Herondas construye una voz poética erudita y docta que inscribe en el texto un lector implícito igualmente sofisticado y sutil. Este presupuesto escriturario entra en colisión, no es difícil de ver, con los personajes del mimo y su contexto narrativo. Sobre esta tensión juega el autor cuando se inmiscuye en su obra como personaje literario. Se instala entonces una suerte de doble ethos, puesto de manifiesto en los dos roles que se reserva para sí el poeta: por un lado patrón doméstico, en el ámbito de su vida privada, y por otro pastor, en la representación alegórica de su vida profesional y pública. Es decir, por un lado, un personaje más de los ordinarios y vulgares del mimo, y por otro, un representante de los de la elite del Museo (recordemos que en el sueño los pastores son los poetas doctos). En los dos planos se subraya el ejercicio de su autoridad, una autoridad que le impide, incluso, una mirada nostálgica hacia la tradición: el autor se declara superior a los modelos del pasado.

65 Cf. Gil.t.t. l.c. (n. 53), p. 102. 
Cuando se trata de juzgar una obra de arte - y la literatura dramática queda inserta en este rótulo - se exponen valores estéticos que parten del reconocimiento de la realidad como fuerza poiética, acorde con el paradigma cultural de la época. Sin embargo, a juzgar por el descuartizamiento de la obra de Herondas, el público docto representado en los mimos no reconoce en ello un valor inherente. En cambio, cuando estos espectadores son gentes del pueblo, las reacciones descriptas revelan una situación muy diversa. Porque estos últimos aprecian abiertamente la belleza en esa imitación de la vida, observación que vale tanto para estatuas y pinturas, para baubones y para literatura dramática. La contradicción parece formar parte de la esencia misma del mimo helenístico. En lugar de resolverla, Herondas la exhibe y la comenta.

¿Pueden las instancias arriba señaladas referirnos algo acerca de la situación real de recepción de la mimografia herondea? Al menos puede darnos pie a repensar si efectivamente el único público compatible con su producción artística era el público letrado de la corte, como su manierismo lingüístico ha inducido a suponer. A propósito, Hunter advierte, en relación con Teócrito, que ningún cliché sobre la historia cultural antigua es más familiar que la creciente separación entre cultura popular y cultura de elite en el período helenístico. ${ }^{66}$ No habría sin embargo razones para pensar que el público de la elite no participara de performances culturales populares. ${ }^{67} \mathrm{Si}$ ése era el caso, lo que la curiosa - y hasta contradictoria - factura del mimo herondeo informaría es sobre la también curiosa y compleja composición de un auditorio de competencias diversas. Sabemos que era una preocupación de los poetas y artistas de la época (todos en el sitial del sophos) el tipo de relación que su arte establecía con el pueblo. Hemos comentado la posición de un Apeles, para quien el vulgo era el único juez. ${ }^{68}$ En la margen opuesta, un contemporáneo de Herondas, Calímaco, públicamente rechazó todo lo que tenía que ver con el pueblo. ${ }^{69}$ Quizá Herondas haya querido reconciliar ambas posturas. Pero todo nos lleva a pensar que, ni el espectador culto disfrutaba plenamente del verismo de las pequeñas cotidianeidades de su mimografia, ni el pueblo terminaba comprendiendo en todo su esplendor un fenómeno tan artísticamente elaborado. De esas tensiones no resueltas, de curiosas mezclas de lo alto y lo bajo, de la belleza que surge de la imitación realista de lo que no es precisamente bello, de un público que puede disfrutar (como la esclava del sueño) pero no interpretar, de otro público que puede interpretar pero no disfrutar (como los doctos de la corte), de todo ello nos informa Herondas en los pasajes que hemos comentado.

\section{Universidad Nacional de La Plata/ CONICET Claudia N. FERNÁNDEZ \\ Argentina \\ cnf@netverk.com.ar \\ claudia_fernandez@huma.fahce.unlp.edu.ar}

66 R. HUNTER, Theocritus and the Archaeology of Greek Poetry, Cambridge, 1996, p. 7.

67 GoLDHILl, o.c. (n. 17), p. 223, en la misma dirección: “(...) many questions about, say, the constitution of the public of Hellenistic literature are simple not answerable with any security."

${ }_{68}$ Plinio, Historia Natural XXXV, 84: vulgum diligentiorem iudicem quam se praeferens.

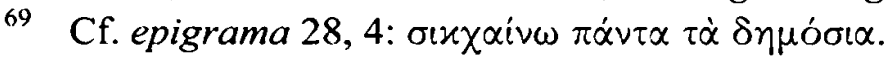

